\title{
I-Three Learning Model (ITLM) to Improve Scholastic Performance- A Case Study
}

\author{
Gururaj Ganapati Gouda $^{1^{*}}$, Pradeep M. D. ${ }^{2}$, Laveena D’Mello ${ }^{3}$, \& Ashvini K. A. ${ }^{4}$ \\ ${ }^{1 *}$ Research Scholar, Srinivas University, Mangalore, Karnataka, India. \\ OrcidID:0000-0001-9339-5862; E-mail: gururajitgi@gmail.com \\ ${ }^{2}$ Research Scholar, School of Law, Alliance University, Bengaluru \& Assistant Professor, \\ College of Social Sciences \& Humanities, Srinivas University, Mangaluru, Karnataka, India. \\ OrcidID: 0000-0003-2561-4749; Email: mdpradeepnair767@gmail.com \\ ${ }^{3}$ Associate Professor, College of Social Sciences \& Humanities, Srinivas University, \\ Mangalore, Karnataka, India. \\ OrcidID: 0000-0003-1935-002X; Email: lavynoronha@gmail.com \\ ${ }^{4}$ Research Scholar, CHRIST University, Bangaluru, Karnataka, India. \\ OrcidID: 0000-0002-5832-4601; Email: ashwinikadlera50172@gmail.com
}

Area of the Paper: Social Science.

Type of the Paper: Research Case Study.

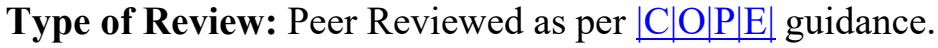

Indexed In: OpenAIRE.

DOI: http://doi.org/10.5281/zenodo.4607208

Google Scholar Citation: IJCSBE.

\section{How to Cite this Paper:}

Gouda Gururaj Ganapati, Pradeep M. D., D’Mello Laveena, \& Ashvini K. A., (2021). IThree Learning Model (ITLM) to improve Scholastic Performance- A Case Study. International Journal of Case Studies in Business, IT, and Education (IJCSBE), 5(1), 50-60. DOI: http://doi.org/10.5281/zenodo.4607208.

International Journal of Case Studies in Business, IT and Education (IJCSBE)

A Refereed International Journal of Srinivas University, India.

(C) With Authors.

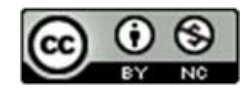

This work is licensed under a Creative Commons Attribution Non-Commercial 4.0 International License subject to proper citation to the publication source of the work.

Disclaimer: The scholarly papers as reviewed and published by the Srinivas Publications (S.P.), India are the views and opinions of their respective authors and are not the views or opinions of the S.P. The S.P. disclaims of any harm or loss caused due to the published content to any party. 


\title{
I-Three Learning Model (ITLM) to Improve Scholastic Performance- A Case Study
}

\author{
Gururaj Ganapati Gouda ${ }^{*}$, Pradeep M. D. ${ }^{2}$, Laveena D’Mello ${ }^{3}$, \& Ashvini K. A. ${ }^{4}$ \\ ${ }^{1 *}$ Research Scholar, Srinivas University, Mangalore, Karnataka, India. \\ OrcidID:0000-0001-9339-5862; E-mail: gururajitgi@gmail.com \\ ${ }^{2}$ Research Scholar, School of Law, Alliance University, Bengaluru \& Assistant Professor, \\ College of Social Sciences \& Humanities, Srinivas University, Mangaluru, Karnataka, India. \\ OrcidID: 0000-0003-2561-4749; Email: mdpradeepnair767@gmail.com \\ ${ }^{3}$ Associate Professor, College of Social Sciences \& Humanities, Srinivas University, \\ Mangalore, Karnataka, India. \\ OrcidID: 0000-0003-1935-002X; Email: lavynoronha@gmail.com \\ ${ }^{4}$ Research Scholar, CHRIST University, Bangaluru, Karnataka, India. \\ OrcidID: 0000-0002-5832-4601; Email: ashwinikadlera50172@gmail.com
}

\begin{abstract}
This manuscript introduces I-Three Learning Model (ITLM) intervention to build competency among scholastically backward children by facilitating easy input, processing and output of information. Child receives information through sensory path ways, learning ability is the capacity of the children to collect, process, retain and retrieve information. Children are unique in mental maturity and learning ability. Reasoning is influenced by the auditory, visual, kinaesthetic and tactile inputs. Competency of children with poor social and emotional skills, learning adjustment and academic performance can be improved by enriching their abilities connected to attention, self-learning, logical thinking, reasoning, adjustment, confidence, comprehension and problem solving. This manuscript is both descriptive and exploratory in nature. On the basis of standard Psychological Assessment, a child studying in the eight standard aged 14 years is identified to be poor in social and emotional skills, learning adjustment and academic performance. This case study is carried to derive the findings of these objectives and establishes that ITLM intervention has certainly improve capacity of receiving, processing and retrieving information in the children and recommends for the usage of model for building competency of scholastically backward students.
\end{abstract}

Keywords: 'I-Three Learning model', Scholastic backwardness, Reasoning, Competency building

\section{INTRODUCTION:}

Learning process should build intelligence, understanding, expression, personality, decision making, response and independence of the children rather than making them more dependent. School education should enrich emotional intelligence and adaptive behavior of the children [1]. Scholastic backwardness is a disorder in the development of scholastic skills such as reading, writing, spelling and numerical computation among children in the age group of 7 to 14 years. Shari et al. (2016) recommends for the need for inclusion of children with learning disabilities in the mainstream of education [2]. Intelligence is the ability to learn, understand and make judgment based on reasoning. Intelligence involves the abilities of reasoning, planning, problem solving, and abstract thinking, comprehension of complex ideas, quick learning and experiential learning [3]. Generally, it is the ability of an individual to receive, process and react to a particular situation. Even though the physical, psychological and social factors influence the development of intelligence, the learning abilities are unique from children between children. Each individual differs in their capacity to respond to a complex situation, learning through experiences, reasoning decisions and solving problems [4]. Intelligence is an ability to solve problems, adapt new knowledge and learn from life's everyday experiences. It comprises of qualities of creativity, interpersonal skills, mental strength, critical abilities, judgment, comprehension and reasoning useful 
to deal with people, object and symbols etc. The authors Pressley et al, (1989) have summated the abilities of acting purposefully, thinking rationally and dealing effectively with the environment within the ambit of intelligence [5].

\subsection{Conceptual Framework:}

Various theories elaborate the theoretical basis of intelligence. In the theory of Multiple Intelligence proposed by Howard Gardner there are nine domains of intelligence found in individuals at varied degrees [6]. Linguistic skills deal with the ability to think in terms of words and usage of communication for expression. Individuals develop a kind of sensitivity to the meaning and sound of words to derive understanding. Mastery over expression, interpretation and usage of language also falls within the ambit of intelligence. It covers the aspects of vocabulary, comprehension and language. Mathematical skills rely on logical ability to solve mathematical problems by using objects and symbols. Spatial skills by which one can perceive the world in three-dimensional way and recreate visual experiences in the absence of physical stimuli. It includes the ability of understanding map, space, distance etc. Body kinesthetic skill is the ability to physically adapt and use the body in a highly skilled ways for expression or goal directed purposes. It includes gracing a movement, agility etc. Musical skills are the ability to sense pitch, melody, rhythm, emotion, tone etc. Interpersonal skills are the ability to interact and act with emotion, distinguish with mood, temperament, motivation and intentions of other people [7]. Intrapersonal skills are the abilities to understand self by understanding their own feelings, guiding the self-emotions, behavior and recognizing the personal strength and weaknesses. Naturalistic skills are the abilities to understand about plants, minerals, climate, weather, other creatures, animals, etc [8]. Lastly the existential skills are concerned with understanding the meaning of life, death, spiritual aspects etc. As per this theory even though there are multiple intelligences Gardner contended that prevalence of high Intelligent Quotient (IQ) will not always ensure success or do not denote on the existence of common sense or inter personal skills. According to the Triarchic theory of intelligence proposed by Robert Sternberg has divided intelligence into three different parts such as analytical intelligence, creative intelligence and practical intelligence. Analytical Intelligence is the ability of an individual to acquire knowledge, store, retain and retrieve information received through senses. It also includes transferring information into the plans, making decisions and solves problems. Analytical intelligence will translate thoughts into performance or actions. This is all about how efficiently individual can process information in order to solve different problems and challenges. Analytical intelligence will monitor solutions and evaluates the results. Individuals who are high in analytical abilities perform better in the classroom learning and examination since they could use knowledge and strategies better [9]. These types of individuals are considered to be smart, do well in any activity and takes up competitive challenges to gain good grade. Creative Intelligence is the ability to deal with new challenges quickly. Individuals will learn to solve different problems in an automatic hence they keep their mind free to handle new problems which require insight and creativity to find a solution. It allows people to find a better approach with the existing or new tasks. It also encourages individuals to compare new knowledge with the previously existing to suggest new ways of putting facts. It enables individuals to think originally. Students with creative intelligence will invent new things. Practical Intelligence is the ability to get out of trouble. It is also the ability to get along with other people. The practical intelligence helps the individuals to deal with their environment, size up a situation and decide what to do, what to adapt, what to change, or how to get out of it [10]. Students do well outside the classroom walls with good social skills and common senses [11].

\subsection{Challenges in School Education:}

Most of the teachers face several challenges in classroom teaching. It may include behavior problems of students, scholastic backwardness, family influence, family problems, academic pressure etc. Whereas individual ability to understand the classroom teaching will become the primary challenges to every student since all other achievement's rests upon this. A study has reported about one student committing suicide per hour in India which seemed to be the highest suicide rate in the world. They report that majority cause behind such suicide is loss of confidence, lack of support, lack of motivation and academic pressure. Students with low intelligence cannot cope with the teaching and learning processes carried out in the classroom since they lack either in understanding, analyzing and interpreting the information provided to them or the tasks given to the students [12 \& 13]. The static 
and crowded education system is stopping the children from gaining knowledge and developing their intelligence. Children fails to develop their behavior, logical thinking, reasoning abilities, knowing self and understanding the social attributes to live in accordance with the social norms. Students are compelled to develop more complex thinking, complicated works and responses. Exams are generating undue pressure among the student community and pushing the children into depression, stress and instigating into suicidal thoughts. In both studies the authors Gouda, \& D'Mello (2019) reported that learning interest and participation of the children in the classroom learning is gradually decreasing due to the effects of corporal punishments practiced in schools, discrimination made based on marks, gender, caste, religion, economic and family background of the students, etc. [14]. Most of the time students in the classroom are quite often found with several behavioral problems including identity seeking, arrogant, bullying, lying etc. The authors Gouda, \& D' Mello (2019) explains about distractive behaviors of the children expressed in the form of making noise, disturbing the class, pinching others, laughing, looking through the window etc. which could be reduced through introducing the cap concept in the class room teaching [15]. Understanding the Intelligent Quotient of the students will help the teachers to use most appropriate pedagogies to enhance their competency through class room learning. The authors Jeevitha, \& Vanitha (2017) reported about the prevalence of multiple intelligence among the students. The findings of the study reveal that female students are having higher multiple intelligence compared to male students and male students possess higher learning styles compared to female students respectively [16]. Prevalence over spoon feeding methods in school education will definitely hamper the learning abilities of the children by reducing their capacity to receive, process and retain information. Theme analyses explained three major challenges in the classroom approach. The firstly it is the instructional challenges related to the unfinished homework, inconsistency in learner's level of intelligence and insistence of the learner to speak in different languages. Secondly, the behavioral psychological challenges relating to the learner's inferiority in speaking, demotivating others, naughtiness, arriving late and inappropriate responses toothers. Thirdly it is the contextual challenge arising due to some specific circumstances. In a study conducted by Neda, \& Ayatollah (2016), the author depicts a challenge of teaching large number of students in a small room resulting in the trouble caused due to more physical distance will hamper the learning since students start talking to the fellow instead of giving attention to the class [17]. In a research Adnan et al, (2018) found that performance of the average students can be improved by the teacher even if large number of students are taught in the single classroom if the teacher manages to make necessary changes in the cognitive approaches used for teaching, adaptation of new teaching techniques as per the need and effective usage of audio-visual aids [18]. Managing time and dealing with student's misbehavior is becoming the most challenging task for the teacher in enhancing students learning ability [19]. Classroom learning is becoming more and more complicated since technology and social Medias have started intervening with human life. Students are distracted and disengaged from the study due to their increasing engagement with mobile phones resulting in the decrease in the learning interest upon class room teaching [20]. Kahkashan (2019), and Archer (2006) have depicted that it is the need of the day to enhance the intelligence and aptitude of the children to accelerate their academic performance with appropriate teaching and learning pedagogies. The different learning strategies, reading, acquiring new knowledge, active participation in the extra-curricular will enhance the academic, intelligence, comprehension etc. [21 \& 22].

\subsection{Scholastic Backwardness:}

Scholastic backwardness is a challenging scenario for developing society. Both teachers and parents are depressed on student's low academic performance. The competitive world has created stress for students through high expectation from their academic performance. There are several reasons behind scholastic backwardness among students, psychological disorders such as attention deficit hyperactivity disorder (ADHD), anxiety disorders, childhood depression, behavioural difficulties, autism, and various emotional problems are commonly associated with scholastic backwardness [23 \& 24]. These problems may lead the child into the functional impairment in the learning. Low school attendance, not being regular to the tuitions, presence of neurodevelopmental disorders and developmental problems are also the major reasons for Scholastic Backwardness [25 \& 26]. Even the poor study habits and various social factors such as lack of support in the home for the study and incompletion of academic tasks due to family problems also contributing to the scholastic backwardness [27]. Students with above problems 
are noticed with a lack of problem-solving skills, lack of decision-making skills and the ability to cope with emotion and stress [28]. Students with scholastic backwardness having cognition abilities significantly lower than those of normal students. These students with lower cognition abilities lack in abilities for immediate analysis, recognition stimulus, or comprehension of information. These students have higher and persistent difficulties in the acquisition knowledge [29]. According to various studies, it is been proved that boys are higher in scholastic backwardness than girls [30]. Family, school and society are equally responsible through their positive and appropriate support for the child's academic performance. Both cognitive and non-cognitive factors are also equally important to improve anyone's academic competence through learning process [31 \& 26]. A good and positive relationship must be enhanced between child and parents. Teachers must provide appropriate support and build confidence among children with scholastic backwardness. An effective teaching approach must be adopted to improve the student's intelligence. Appropriate nurturing from the prenatal period such as nutrition, regular screening of vision and hearing will help both parents and teachers prevent poor school performance [32 \& 33].

\section{OBJECTIVES :}

The study answers the following questions firstly, how does the I-Three Learning Model contribute to the development of receiving, processing and retrieving of the information to improve social and emotional skills, learning adjustment and academic performance among students. It also elaborates on the various competencies which students acquire with the help of ITLM.

\section{RESEARCH METHOD :}

This scholarly manuscript is both descriptive and exploratory in nature. On the basis of direct observation, interview, parent's and teacher's feedback a child studying in the eight standard aged 14 years is identified to be poor in social skills, adjustment, and learning. After this assessment the child was engaged in I-Three Learning process for six months with the help of family members and teachers. After the completion of six months of intervention once again parent's and teacher's feedback are taken. Systematic observation throughout the implementation of ITLM and face to face interview under the supervision of Ashwini K. A. (certified psychologist) is done. The results obtained from the preassessment and post-assessment were described and suggestions are drawn. Both primary and secondary data methods are used for the study. This case study was carried to derive the findings of this study.

\section{I-THREE LEARNING MODEL (ITLM):}

This study establishes that ITLM intervention will certainly improve closure, clerical, numerical, psycho motor, reasoning, spatial and verbal capacity of the scholastically backward child and recommends for the usage of model for building competency of scholastically backward students. This study introduces an innovative learning approach called 'I-Three Learning Model'(ITLM) to improve the utility of the classroom teaching and helps in enhancing the intelligence and aptitude of the learners with easy input, processing and output of information. ITLM describes basically about three learning competencies and its outcome based on the Post Intervention test result. The aim of ITLM is to assist students for the better inputs of information, improving the competency in comprehension of the information and preparing them to produce better outputs of the information [34]. ITLM will exemplify developmental progression of scholastically backward learner with more learning-directed strategies and student-centered representations to connect and combine different methods of learning [35]. Since students of a class are not at equal levels of maturity or learning intelligence, ITLM through multiple modalities can be adopted to enhance the learning abilities of the students. Multiple modalities are varied techniques of engaging students such as activities, brain gym, brain storming, yoga, reading, group discussion, activities and experiments usage of audio-visual aids in teaching and learning process etc. If teachers continuously rely only on one method the monotony increases and students loses interest in learning hence, they stop grasping things. This may distract the attention span of students and learning stands still [36].

\subsection{Interventions under ITLM:}

This model basically provides three different types of interventions described below. 
(a) Information Inputs: Individual receives information from the external world through their sensory pathways (Figure-02). These organs include eyes, nose, tongue, ear and skin which is also called as sensory organs. Different senses in the human body receive various information about the same objects or events in the external world. The information received through this process is analyzed for further actions [37]. Human brain is the mother board of the human body which controls and communicates to the rest of the human body organs. The brain stimulates the senses in order to send information received. So that brain controls the thoughts with the help of frontal lobe, parietal and temporal lobe. When the brain goes through irreparable damage it impacts on overall or partial functions of it [38 \& 39].

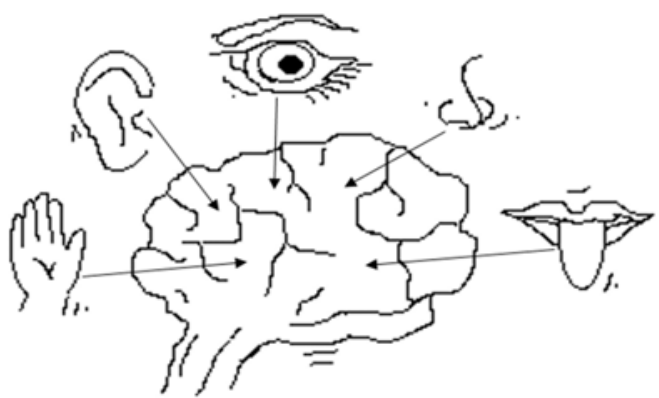

Fig. 1: Information Input

Information input is the ability of the children to acquire, store and retrieve information received through the sensory gateways. The process is carried out either of the forms of auditory input, visual inputs, kinesthetic inputs and tactile inputs [40].

(b) Information Processing: It is the ability of an individual to solve problems to facilitate mind to handle freely on different problems which requires insight and creativity. (Figure 03).

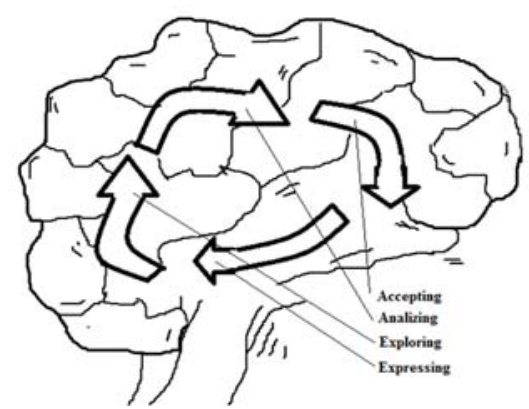

Fig. 2: Information Processing

Information processing is an action-oriented task performed inside the human brain after receiving the information from the external world through sensory organs. It is unique from person to person. In a research the authors found that students with high intelligence may not restrict themselves to traditional teaching but they try to provide unique answers but sometime for which they might get reprimanded [5]. Information processing is carried through multiple sub actions. First action is 'accepting' the information supplied from the external world which generates interest to give attention to a particular aspect. Second action deals with 'analyzing' the information which is already accepted by keeping the past experience and knowledge to derive better understanding on it. Third action is 'exploration' where an individual makes a new decision on the basis of analysis to derive a new idea, plan, decision, action and reaction. The last action is 'expression' where the brain suggests the respective organs in the human body to put forth the decision derived [41 \& 42].

(c) Information Output: It is an ability to implement the decision by performing some external action. It is how people deal with their environment with right reaction in the right situation by taking decision 
by deciding what to do and what not to do. The authors Shari et al., (2016) reported that, few students having high intelligence will do well both inside and outside the classroom by exhibiting good social skills and common sense [43]. The frontal lobe in the human brain mainly works on the implementation action-oriented representations [44]. Family and school were found to be more effective on student's decision making process and parents and teachers play an important role to influence the students for the adopting skills of problem solving [45].

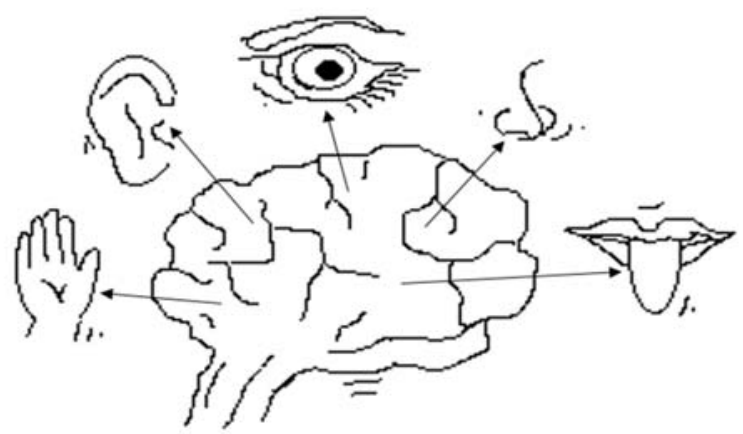

Fig. 3: Information Output

\section{FINDINGS :}

(a) Case Profile: This is a case study conducted to derive the impact of ITLM to develop intelligence and aptitude among the scholastically backward student. ITLM intervention is executed upon a girl of fourteen years of age studying in the $8^{\text {th }}$ Standardliving in a coastal village of Dakshina Kannada district in the state of Karnataka. On the basis of direct observation, interview, parent's and teacher's feedback she is identified to be poor in social skills, adjustment, and learning.

(b) Family history: Subject is belonging to a nuclear family. Her father (46 years) who is a graduate but self-employed and mother (40 years) is PUC dropout and a home maker. The subject has an elder brother (aged 16 years) studying in the $10^{\text {th }}$ standard and a younger brother (aged 12 years) studying in the $6^{\text {th }}$ standard. Both father and mother show so much of care, support and affection to the respondent since she is the only girl child they had. During interview subject found weak in social and learning skills due to too much sensitivity in parental care such as not allowing her to mingle and interact with others, not encouraging for outdoor games thinking that she gets injured, even making her too much dependent. The subject was hesitant to mingle with friends and scared to talk to teachers or people. She was also found facing trouble to remember information taught by the teachers or parents. Father and mother never understood her inability in developing good social skills, lack of confidence to be independent and inferiority to engage her selves to think creatively to fix any problem. Parents never realized that too much affection is creating weakness rather than strengthening the subject. Parents were always next to her to help for accomplishing any of her tasks. This has never provided an opportunity where she could invest her aptitude and intelligence in her day-to-day living. Family tree is specified in the figure 01 .

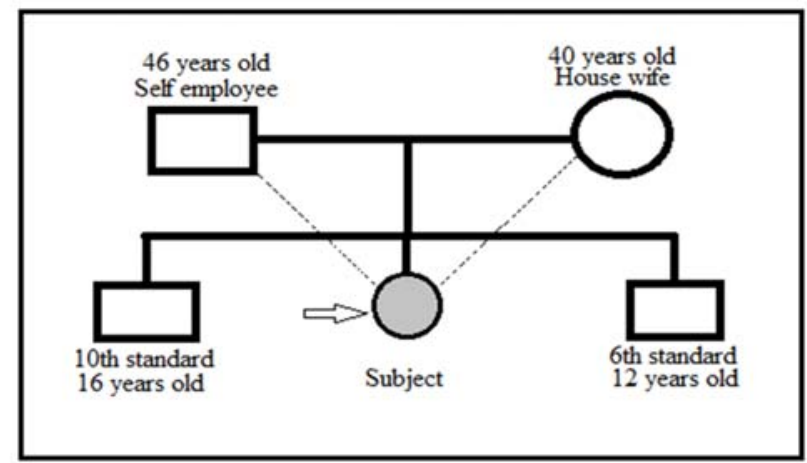

Fig. 4: Family tree of the case (Subject) 
(c) Symptoms Diagnosed: Subject expressed several signs of disabilities including problems in understanding and analyzing the information compared to her classmates, poor social skills in playlearn situations with other children, poor self-care and hygiene. She also expressed about trouble in speaking, remembering things, connecting to action and difficulty in solving problems or logical thinking in the day to day life.

(d) Usage of ITLM Associative Interventions: The study subject was provided with ITLM associated interventions through the following strategies. Under the information input, the subject was exposed to multi style learning by teaching with different methods to transmit knowledge. Learning environment was supported in such a way to develop the self-confidence, self-respect and self-help to the subject [46]. Information was provided about the importance of learning and aptitude development by highlighting her potentials. Multiple methods such as read-write method, lecture, interaction with friends, audio records, observation of body language, facial expressions, video aids, external environment, physical involvement. Teaching and learning activities such as practices and hands-on training were also provided. Subject was encouraged to have a good conversation with her counselor, teachers, friends and parents to improve her confidence [47]. The girl was given several opportunities to engage herself in the process of decision making. She was encouraged to compare new information with her knowledge to derive new ways of putting facts together. Observations were carried to evaluate the familiarity with the novel tasks and how effectively subject could process information, think originally and generate right action in the right situation. Chances were provided to the subject to perceive information in the correct manner. The subject was provided with tasks such as brain storming, street play, pick\& speak, question \& answer, stress interview where she could come up with her own ideas and put herself into the action. She was encouraged to confidently implement her decisions, ideas and the plans in a given situation. She was also appreciated and supported in making her output decisions based on her information inputs and processing [48]. The girl was taught various skills to use her communication, body language, facial expressions effectively in her involvement both at the classroom and family. These strategies made her actively respond and involve physically and mentally in the teaching process to development aptitude and intelligence [49].

\section{DISCUSSION :}

After executing the ITLM along with associated multiple approaches for a period of six months the following results were obtained. Active involvement of the client in ITLM she showed improvement in her intelligence and aptitude by showing both physical and psychological presence in the classroom, improved comprehension, develop capacity to make decisions and building confidence in her. This indicates that I-Three Learning Model is effective and appropriate to improve scholastically backward learner [50]. In order to execute ITLM in an effective manner the following recommendations are suggested. School teachers should be trained to adopt ITLM to improve the social and emotional skills, adjustment towards learning and academic among the children. Since researches have reported that the human brain is designed to develop, learn and operate logically according to the environment. Hence ITLM is identified to be the best method to improve scholastically backward students to develop in the aspects of reception, processing and output of information. There are unique ways to learn different aspects and respond in the proper way therefore, teachers and students should engage actively to derive the expected result at lease for a period of six months. Schools must show interest in procuring necessary classroom resources to adopt ITLM in an effective manner. Parents should play an active role to provide an appropriate support throughout the process of ITLM. Both teachers and parents to be trained to use ITLM. Intelligence is an ability to acquire, process, retain and retrieve information. This model deals with different auditory inputs, visual inputs, kinesthetic inputs and tactile inputs. Aptitude development is the most essential part of the teaching and learning process which will improve the student's overall development [51]. Therefore, teachers are suggested to adopt various skills and techniques to effectively teach using ITLM. This study suggests for further investigation on students with poor social and emotional skills, learning adjustment and academic performance using ITLM model to derive the impact of this model on different age group.

\section{CONCLUSION :}

The results of the case study showed that experiences through I-Three Learning Model along with 
associated multiple strategies will certainly improve the information inputs, processing and output among the children. It develops the traits of self-learning, comprehension, confidence and adjustment among the children with poor social and emotional skills, learning adjustment and academic performance. Educational institutions, voluntary organizations and various stakeholders like child mental health providers are recommended to adopt ITLM model for overall enhancement of needy children.

\section{REFERENCES}

[1] Salovey, P., \& Mayer, J. D. (1990). Emotional intelligence. Imagination, cognition and personality, 9(3), 185-211.

[2] Shari, M., \& Vranda, M. N. (2016). Attitude of Primary School Teachers towards Children with Learning Disabilities. Journal of Indian Association for Child \& Adolescent Mental Health, 12(4),323-335.

[3] Schaefer, B. A., \& Mc Dermott, P. A. (1999). Learning Behavior and Intelligence as explanations for Children's Scholastic Achievement. Journal of School Psychology, 37(3), 299-313.

[4] M. D, Pradeep and Kalicharan, M. (2016). Life Centric Skill Enrichment Framework-An effective Pedagogy for Empowerment. International Journal of Computational Research and Development (IJCRD), 1(1), 40-46.

[5] Pressley, M., Borkwski, J. G., \& Schneider, W. (1989). Good information processing: What it is and how education can promote it. International Journal of Educational Research, 13(8), 857-867.

[6] Gardner, H., \& Hatch, T. (1989). Educational implications of the theory of multiple intelligences. Educational researcher, 18(8), 4-10.

[7] Itagi, Gururaj, \& D'Mello, Laveena (2019). Academic Excellence through Multi-Sensory Approach: A Model for Classroom Teaching. International Journal of Management, Technology, and Social Sciences (IJMTS), 4(2), 74-86.

[8] Helding, L. (2009). Howard Gardner's Theory of Multiple Intelligences. Journal of Singing, 66(2), 193-199.

[9] Sternberg, R. J. (2018). Speculations on the role of successful intelligence in solving contemporary world problems. Journal of Intelligence, 6(1), 1-10.

[10] Sternberg, R. J. (1997). The concept of intelligence and its role in lifelong learning and success. American Psychologist, 52(10), 1030-1037.

[11] Eysenck, M. W. (1986). Beyond IQ: A Triarchic Theory of Human Intelligence. By R. J. Sternberg. Cambridge University Press, Cambridge 1985, Psychological Medicine, 16(03), $713-$ 715 .

[12] Jayanthi, P., Thirunavukarasu, M., \& Rajkumar, R. (2015). Academic stress and depression among adolescents: A cross-sectional study. Indian pediatrics, 52(3), 217-219.

[13] Finn, J. D., \& Rock, D. A. (1997). Academic Success among Students at Risk for School Failure. Journal of Applied Psychology, 82(2), 221-234.

[14] Gouda Gururaj, Ganapati, \& D'mello, Laveena (2019). A Study on the Teacher-Student Relationship and its impact on the behaviour of High School Students. International Journal of Case Studies in Business, IT, and Education (IJCSBE), 3(1), 28-34.

[15] Gouda Gururaj, Ganapati, \& D' Mello, Laveena (2019). Introducing “Cap Concept” in a Class Room Learning for the students to achieve success. International Journal of Management, Technology, and Social Sciences (IJMTS), 4(1), 38-45.

[16] Jeevitha, S., \& Vanitha, J. (2017). A Study of Multiple Intelligence in relating to Learning Style among Higher Secondary Students. International Journal of Research - Granthaalayah, 5(6), 310 319. 
[17] Soleimani, N., \& Razmjoo, A. (2016). Classroom Management Challenges: An Account of EFL Teachers at Private Language Institutes. Anatolian Journal of Education, 1(1), 51-69.

[18] Adnan Tahir, Akhtar Iqbal, Abrar Hussain, Qureshi (2018). Classroom Management: A Challenging Part in Beginning English Teachers' Career Entry Stage. International Journal of English Linguistics, 8(4), 155-163.

[19] Nguyen, N. T., Tran, H. A., \& Luu, L. N. (2017). Classroom management: Difficulties facing fasttrack teacher-trainees in the tutoring program. The English Teacher, 45(2), 84 - 95

[20] Noronha, L. (2016). Implication of Academic Stress in Adolescents. International Journal of Scientific Research and Modern Education (IJSRME), 1(1), 320-327

[21] Kahkashan, Tabassum (2019). An intelligent Self-adaptable application to Support Children Education and Learning. International Journal of Computer Science \& Information Technology (IJCSIT), 10(6), 23-30.

[22] Archer, A. (2006). A Multimodal Approach to academic Literacy Practices: Problematizing the Visual/Verbal Divide. Language and Education, 20(6), 449-462.

[23] Bruce F. Pennington (2009). Diagnosing Learning Disorders ( $2^{\text {nd }}$ ed.). The Guilford Press. pp-2834.

[24] Tilly Mortimore (2008). Dyslexia and Learning Style (2 ${ }^{\text {nd }}$ ed.). John Wiley \& Sons Ltd. pp-50-63.

[25] Shah, C. G., \& Buch, P. M. (2019). Prevalence of specific learning disabilities among Gujarati medium primary school children. Indian Journal of Child Health, 6(6), 283-286.

[26] Beniwal, R. P., Sachdev, A., Kumar, V., Bhojak, M. M., \& Tambi, A. (2018). Scholastic backwardness among school students: Prevalence and correlates. Telangana Journal of Psychiatry, 4(1), 11-15.

[27] Shashidhar, S., Rao, C., \& Hegde, R. (2009). Factors affecting scholastic performances of adolescents. The Indian Journal of Pediatrics, 76(5), 495-499.

[28] Anita Bhat \& Vijayalaxmi Aminabhavi (2011). Home Environment and Psychosocial Competence of Adolescents. Journal of Psychology, 2(1), 57-63

[29] Shenoy, J., \& Kapur, M. (1996). Prevalence of scholastic backwardness among five- to eight-yearold children. Indian journal of psychiatry, 38(4), 201-207.

[30] Nagarathna, D. A. S. (2014). Socioeconomic Status among Scholastic Backward Children. Journal of the IAP Karnataka State Branch, 29(2), 45-48.

[31] Santosh, A. (2014). Scholastic backwardness in children attending normal school. Archives of Mental Health, 15(2), 251-251.

[32] Karande, S. Sawant, S., Kulkarni, M., Galvankar, P., Sholapurwala, R. (2005). Comparison of Cognition Abilities Between Groups of Children with Specific Learning Disability Having Average, Bright Normal and Superior Nonverbal Intelligence. Indian Journal of Medical Sciences, 59(3), 95-103.

[33] Sinu, E., \& Nathiya, E. (2012). High Academic Achievement: Role of Parents, Teachers and School. Journal of School Social Work. 9(3), 1-32.

[34] Black, J. B., Segal, A., Vitale, J., \& Fadjo, C. L. (2012). Embodied cognition and learning environment design. Theoretical foundations of learning environments, 2(1), 198-223.

[35] Vasiliki, Papageorgiou, \& Petros, Lameras (2017). Multimodal Teaching and Learning with the Use of Technology: Meanings, Practices and Discourses. $14^{\text {th }}$ International Conference on Cognition and Exploratory Learning in Digital Age. Retrieved from: https://files.eric.ed.gov/fulltext/ED579485.pdf

[36] Johnson, R. T., \& Johnson, D. W. (2008). Active learning: Cooperation in the classroom. The annual report of educational psychology in Japan, 47(1), 29-30. 
[37] Driver, J., \& Spence, C. (2000). Multisensory perception: beyond modularity and convergence. Current biology, 10(20), 731-735.

[38] Mero, C. M. M., \& Martinez, M. E. M. (2020). Importance of brain knowing for receiving information. International journal of social sciences, 3(1), 7-12.

[39] Chi, M. T., \& Wylie, R. (2014). The ICAP framework: Linking cognitive engagement to active learning outcomes. Educational psychologist, 49(4), 219-243.

[40] Reid, J. M. (1987). The Learning Style Preferences of Esl Students. Tesol Quarterly, 21(1), 87111.

[41] Wang, Y., \& Chiew, V. (2010). On the cognitive process of human problem solving. Cognitive systems research, 11(1), 81-92.

[42] Recker, J., Reijers, H. A., \& van de Wouw, S. G. (2014). Process model comprehension: the effects of cognitive abilities, learning style, and strategy. Communications of the association for information systems, 34(9), 199-222.

[43] St Gibson, A. C., Lambert, E. V., Rauch, L. H., Tucker, R., Baden, D. A., Foster, C., \& Noakes, T. D. (2006). The role of information processing between the brain and peripheral physiological systems in pacing and perception of effort. Sports Medicine, 36(8), 705-722.

[44] Sakai, K., Ramnani, N., \& Passingham, R. E. (2002). Learning of sequences of finger movements and timing: frontal lobe and action-oriented representation. Journal of neurophysiology, 88(4), 2035-2046.

[45] Güçray, S. S. (2003). The Analysis of Decision-Making Behaviors and Perceived Problem Solving Skills in Adolescents. Turkish Online Journal of Educational Technology-TOJET, 2(2), 29-37.

[46] Davies, T. (2000). Confidence! Its role in the creative teaching and learning of design and technology. Journal of Technology Education, 12(1), 18-31.

[47] Ronteltap, F., \& Eurelings, A. (2002). Activity and interaction of students in an electronic learning environment for problem-based learning. Distance Education, 23(1), 11-22.

[48] Sigrist, R., Rauter, G., Riener, R., \& Wolf, P. (2013). Augmented visual, auditory, haptic, and multimodal feedback in motor learning: a review. Psychonomic bulletin \& review, 20(1), 21-53.

[49] Reeve, J., \& Jang, H. (2006). What teachers say and do to support students' autonomy during a learning activity. Journal of educational psychology, 98(1), 209-218.

[50] Gururaj Ganapati, Gouda, \& Laveena D’ Mello (2019). Excellence through Value Education - A Case Study of Sharada Vidyanikethana Public School. International Journal of Case Studies in Business, IT, and Education (IJCSBIE), 3(1), 9-19.

[51] Schneider, W., Körkel, J., \& Weinert, F. E. (1989). Domain-specific knowledge and memory performance: A comparison of high-and low aptitude children. Journal of educational psychology, 81(3), 306-312.

$* * * * * * * * * * *$ 